\title{
Os desafios do complexo da tristeza parasitária bovina - TPB
}

\author{
The challenges of the bovine parasity saddle complex - BPS \\ Los retos del complejo de la tristeza parasitaria bovina - TPB
}

Recebido: 16/05/2021 | Revisado: 23/05/2021 | Aceito: 25/05/2021 | Publicado: 10/06/2021

\author{
Mariah Oliveira Costa \\ ORCID: https://orcid.org/0000-0002-1983-7973 \\ Centro Universitário de Mineiros, Brasil \\ E-mail: mariahcosta007@gmail.com \\ Monique Resende Carvalho \\ ORCID: https://orcid.org/0000-0001-8217-938X \\ Centro Universitário de Mineiros, Brasil \\ E-mail: monique_r_c@ @otmail.com \\ Lianna Ghisi Gomes \\ ORCID: https://orcid.org/0000-0003-0909-2426 \\ Universidade Federal de Mato Grosso, Brasil \\ E-mail: liannaghisi@gmail.com \\ Matias Bassinello Stocco \\ ORCID: https://orcid.org/0000-0003-2069-1788 \\ Universidade Federal de Mato Grosso, Brasil \\ E-mail: matiasnave@hotmail.com \\ Paulo Roberto Spiller \\ ORCID: https://orcid.org/0000-0002-4659-4647 \\ Universidade de Cuiabá, Brasil \\ E-mail: paulo_spiller@hotmail.com \\ Eduardo Ferreira Faria \\ ORCID: https://orcid.org/0000-0003-1108-7933 \\ Universidade de Cuiabá, Brasil \\ E-mail: eduffaria@gmail.com \\ Elce Nunes Nogueira da Costa Nogueira \\ ORCID: https://orcid.org/0000-0002-2342-5488 \\ Centro Universitário de Mineiros, Brasil \\ E-mail: elceletras@hotmail.com \\ Priscila Chediek Dall' Acqua \\ ORCID: https://orcid.org/0000-0001-5781-4492 \\ Centro Universitário de Mineiros, Brasil \\ E-mail: priscila.chediek@unifimes.edu.br \\ Eric Mateus Nascimento de Paula \\ ORCID: https://orcid.org/0000-0002-5948-1860 \\ Centro Universitário de Mineiros, Brasil \\ E-mail: ericmateus@unifimes.edu.br \\ Andresa de Cássia Martini Mendes \\ ORCID: https://orcid.org/0000-0002-2553-3685 \\ Centro Universitário de Mineiros, Brasil \\ E-mail: andresa.martini@unifimes.edu.br
}

\begin{abstract}
Resumo
Este artigo apresenta os principais desafios do complexo da Tristeza Parasitária Bovina (TPB), a partir de revisão literária sobre o tema. A TPB é um complexo de enfermidades causadas pelos protozoários Babesia bovis e Babesia bigemina combinados com a bactéria Anaplasma marginale, os quais são transmitidos pelo vetor Rhipicephalus (Boophilus) microplus (carrapato-do-boi) ao seu hospedeiro bovino, impactando negativamente a saúde do animal e acarretando milhões de prejuízos à economia rural, seja no combate e controle do parasito, ou em gastos com medicamentos, de acordo com dados do Ministério da Agricultura, Pecuária e Abastecimento (MAPA), e do IBGE. Os principais métodos de controle e tratamento às doenças causadas por B. bovis, B. bigemina e A. marginale, atualmente, se resumem no combate ao vetor com aplicação de produtos químicos, como os acaricidas, aos animais contaminados. Entretanto, os desafios desse método residem na prática de aplicação em sequência e com frequência desses produtos químicos na população bovina, o que provoca, geralmente, a configuração de carrapatos multirresistentes aos agentes químicos. Diversos estudos têm mostrado pequenos resultados com tratamentos homeopáticos e rotação de pastagem, tratamentos alternativos para o combate ao parasito Rhipicephalus microplus. Em 2020, o MAPA lançou obra orientativa com a metodologia Tratamento Bovino Seletivo (TBS), cujo objetivo é acompanhar caso a caso a população bovina contaminada para se fazer o processo seletivo dos animais, de modo que
\end{abstract}


os animais doentes são tratados. Para garantir êxito, oferece-se o Programa de Controle Seletivo do Carrapato Bovino (PCSCB), criado pela Universidade Federal do Paraná.

Palavras-chave: Carrapatos; Hemoparasita; Tristeza parasitária.

\begin{abstract}
This article presents the main challenges of the Bovine Parasitic Tristeza (TPB) complex, based on a literary review on the subject. TPB is a complex of diseases caused by the protozoa Babesia bovis and Babesia bigemina combined with the bacterium Anaplasma marginale, which are transmitted by the vector Rhipicephalus (Boophilus) microplus (tick) to its bovine host, negatively impacting the bovine host. animal health and causing millions in losses to the rural economy, either in the fight and control of the parasite, or in expenses with medicines, according to data from the Ministry of Agriculture, Livestock and Supply (MAPA), and the IBGE. The main methods of control and treatment of diseases caused by B. bovis, B. bigemina and A. marginale, at present, are summarized in the fight against the vector with the application of chemical products, such as acaricides, to contaminated animals. However, the challenges of this method lie in the practice of sequentially and frequently applying these chemicals to the bovine population, which generally causes the configuration of multi-drug resistant ticks to the chemical agents. Several studies have shown small results with homeopathic treatments and pasture rotation, alternative treatments to combat the Rhipicephalus microplus parasite. In 2020, MAPA launched a guide with the Selective Bovine Treatment (TBS) methodology, whose objective is to monitor the contaminated bovine population case by case to carry out the animal selection process, so that sick animals are treated. To ensure success, the Selective Control Program for Bovine Ticks (PCSCB) is offered, created by the Federal University of Paraná.
\end{abstract}

Keywords: Tick; Hemoparasite; Parasitic sadness.

\title{
Resumen
}

Este artículo presenta los principales retos del complejo de la Tristeza Parasitaria Bovina (TPB), a partir de una revisión bibliográfica sobre el tema. El TPB es un complejo de enfermedades causadas por los protozoos Babesia bovis y Babesia bigemina combinados con la bacteria Anaplasma marginale, que son transmitidos por el vector Rhipicephalus (Boophilus) microplus (garrapata del ganado) a su huésped bovino, impactando negativamente en la salud del animal y causando pérdidas millonarias a la economía rural, ya sea en el combate y control del parásito, o en el gasto en medicamentos, según datos del Ministerio de Agricultura, Ganadería y Abastecimiento (MAPA), y del IBGE. Los principales métodos de control y tratamiento de las enfermedades causadas por B. bovis, B. bigemina y A. marginale, actualmente, se resumen en el combate al vector con la aplicación de productos químicos, como los acaricidas, a los animales contaminados. Sin embargo, los retos de este método radican en la práctica de aplicar estos productos químicos de forma secuencial y frecuente en la población ganadera, lo que suele provocar la configuración de garrapatas multirresistentes a los agentes químicos. Varios estudios han mostrado pequeños resultados con tratamientos homeopáticos y rotación de pastos, tratamientos alternativos para combatir el parásito Rhipicephalus microplus. En 2020, el MAPA puso en marcha un trabajo de orientación con la metodología Tratamiento Selectivo Bovino (TBS), cuyo objetivo es monitorear caso por caso la población bovina contaminada para hacer el proceso selectivo de los animales, de manera que los animales enfermos sean tratados. Para garantizar el éxito, se ofrece el Programa de Control Selectivo de Garrapatas Bovinas (PCSCB), creado por la Universidad Federal de Paraná.

Palabras clave: Garrapatas; Hemoparásito; Tristeza parasitaria.

\section{Introdução}

Como maior produtor de bovinos do mundo, o Brasil tem na produção de leite e/ou carne a principal fonte de renda das propriedades rurais, particularmente as pequenas. Nesse sentido, no manejo do gado, é preciso considerar as várias enfermidades de podem acometê-lo, entre as quais a tristeza parasitária bovina, a qual provoca quedas de produtividade, retardo nas idades de abate e reprodutiva, transmissão de doenças, alta morbidade, ou mesmo a morte de alguns animais, o que gera impactos econômicos consideráveis na cadeia do agronegócio brasileiro. Deste modo, a sanidade animal é de suma importância para a manutenção da pecuária como fonte de renda (Camargo et al., 2017)

Segundo dados do Instituto Brasileiro de Geografia e Estatística (IBGE), apesar da queda representativa no rebanho bovino brasileiro no ano de 2018, o Brasil ainda possui o maior rebanho bovino comercial, cerca de 213,5 milhões de cabeças, contexto em que o estado de Mato Grosso responde por 14,1\% desse cômputo, embora o município de São Félix do Xingu-PA apresente o maior efetivo e produção (IBGE, 2020). 
Permanecer e garantir esse ranking requer medidas enérgicas entre produtores e agências de controle governamentais e/ou privadas para suprimir ou minimizar a recorrência da TPB, caso contrário os prejuízos à produção bovina pode chegar US\$ 500 milhões anuais no país, de acordo com Martins (2020).

Estudos para o controle e prevenção desta enfermidade se fazem necessários, para que haja uma constante atualização sobre as tecnologias disponíveis e para o desenvolvimento econômico do setor produtivo. A abrangência e a constante atualização é o que fomenta o desenvolvimento de novas tecnologias e estratégias de controle, bem como no desenvolvimento de vacinas viáveis (Silva et al., 2021).

Diante do exposto, este artigo propôs apresentar os aspectos epidemiológicos, clínicos e patológicos da TPB, bem como discorrer sobre possibilidades de controle e tratamento da doença no Brasil.

Para isso, realizou extensa pesquisa bibliográfica na literatura da área, além de acompanhar dados de agências nacionais de controle sobre a doença, no sentido de atualizar e corroborar com as principais discussões sobre o assunto.

\section{Metodologia}

A pesquisa utilizada, para produção dessa revisão bibliográfica, ocorreu através da consulta em plataforma de dados PubMed e Scielo e ainda a ferramenta de busca Google acadêmico. Vale destacar que foram utilizados filtros específicos de data, entre 2000 e 2021, além de ter sido analisado apenas trabalhos na língua portuguesa, utilizando descritores como: Tristeza parasitária e controle de carrapatos.

\section{Resultados e Discussão}

A Tristeza Parasitária Bovina (TPB), como é conhecida no Brasil, é o nome comum dado a infecções causadas por Babesia e Anaplasma. Sua principal forma de transmissão é através de carrapatos Rhipicephalus (Boophilus) microplus (carrapato-do-boi), e moscas hematófagas (Stomoxys calcitrans, tabanídeos e culicídeos). No caso da Anaplasmose, a transmissão também pode ocorrer por meio de agulhas hipodérmicas, instrumentos cirúrgicos contaminados, transfusões de sangue, ou, ainda, por transplante de embriões (Cassol, 2020).

No contexto brasileiro, os principais agentes etiológicos desse tipo de enfermidade são o Anaplasma marginale, a Babesia bovis, e a Babesia bigemina (Quevedo \& Quevedo, 2020).

O carrapato-do-boi, ectoparasito responsável pela transmissão de hemoparasitas que causam a TPB, costuma ser o principal parasito citado pelo produtor rural como responsável pelos prejuízos econômicos causados ao rebanho bovino. Presente em todo território nacional, sua entrada no país está relacionada às expedições de transportes de animais domésticos parasitados, durante o século XVIII (Martins, 2020), particularmente da Ásia, espalhando-se pela América do Sul, Austrália e África. Ele possui duas fases de vida: "uma livre, em que vive no ambiente, e a outra no hospedeiro, onde realiza sua ovipostura, a qual leva a sua morte logo após" (Pasquali et al., 2019).

O recorrente clima quente nas principais regiões do país contribui para a permanência e vida longa desse parasito. Assim, na sequência, são apresentadas as particularidades dos hemoparasitas que compõem o complexo da Tristeza Parasitária Bovina.

A babesiose bovina é um tipo de enfermidade transmitida pelo carrapato-do-boi (Ripicephalus (Boophilus) microplus), e se manifesta nesse parasito por meio de dois tipos de protozoários: Babesia bovis e Babesia bigemina. Como característica principal, as babésias apresentam elevado grau de infecção e multiplicação por eritrócitos. No caso da babesia bovis, tem-se nela a espécie mais patogênica encontrada nos bovinos (Quevedo \& Quevedo, 2020).

De acordo com dados do Ministério da Agricultura, Pecuária e Abastecimento (BRASIL, 2020), estima-se um prejuízo de aproximadamente US\$ 3 bilhões anuais ocasionados pela presença recorrente do carrapato-do-boi no rebanho 
nacional. Além disso, de acordo com o órgão, os custos relacionados ao tratamento de doenças transmitidas pelo parasito, sejam elas a babesiose ou a anaplasmose, chegam a alcançar US\$ 18 bilhões/ano.

Conforme Pasquali et al. (2019):

O Rhipicephalus (Boophilus) microphilus é um ectoparasito relevante na bovinocultura por fazer parte da família Ixodideos, o que significa que sua alimentação é por hematofagia, ingerindo cerca de $3 \mathrm{ml}$ de sangue causando um grande prejuízo econômico tanto no gado leiteiro por reduzir a produção de leite, quanto no produto do gado de corte por causar danos no couro pela inflamação oriunda da fixação do carrapato (Pasquali et al., 2019).

Como se observa, os prejuízos à saúde bovina e os prejuízos à economia da produção bovina nacional podem ser desastrosos, caso não haja diagnóstico e controle adequado das doenças transmitidas por esse parasito.

$\mathrm{Na}$ composição do complexo da TPB, a Anaplasmose é causada pela bactéria Anaplasma marginale, também transmitida por carrapatos, ou por insetos hematófagos. Entretanto, a forma iatrogênica é uma das possibilidades de transmissão dessa doença, principalmente no manuseio de instrumentos cirúrgicos contaminados, material de vacinação, transfusões de sangue etc (Ulsenheimer et al., 2020; Quevedo \& Quevedo, 2020).

Segundo Quevedo e Quevedo (2020), enquanto o período de incubação da Babesia sp. compreende um intervalo entre 7 a 10 dias, para a Anaplasma marginale esse período é superior a 20 dias. Ademais, os pesquisadores ressaltam que a transmissão do protozoário Babesia bovis ao bovino manifesta -se logo no primeiro dia de parasitismo por larvas do carrapato Ripicephalus microplus. Outro ponto é a possibilidade de transmissão congênita de Babesia bovis, cuja consequência é a ocorrência de natimortos, ou o animal morrer antes de completar um mês de vida.

No caso da Babesia bigemina, a inoculação de esporozoítos em bovinos configura-se após 8 dias de parasitismo, contexto em que o carrapato atinge o estado ninfal. Nesse quadro, é importante se atentar que, caso animais sem imunidade à Babésia ou à anaplastamose, sejam colocados em campos infestados de carrapatos, eles podem, entre 7-10, desenvolver babebiose por B, bovis; entre 15-20, babesiose por B. bigemina; e, ainda, após 20 dias, anaplasmose, completando-se o complexo da Tristeza Parasitária Bovina (Quevedo \& Quevedo, 2020).

Os sintomas da babebiose podem variar, fator que definirá a gravidade da situação, de modo que o animal pode não apresentar nenhum tipo de sintoma, ou apresentar sintomas variáveis entre leves e severos. Neste último caso, as complicações decorrentes da infecção com babebiose podem levar o animal à morte, como aponta Gonçalves (2020).

De acordo com Gonçalves (2020), um quadro infeccioso por babesia, geralmente, caracteriza-se pela apresentação de febre alta, calafrios, dores musculares ou articulares e fadiga, embora possam ser encontrados outros sintomas menos comuns como:

- dor abdominal;

- náusea;

- contusões na pele;

- icterícia da pele e olhos.

Segundo Cassol (2020), "Clinicamente esta doença se manifesta por febre, anemia (mucosas ocular, oral e vaginal), icterícia, hemoglobinúria, prostração, desidratação, falta de apetite e emagrecimento; [...] incoordenação motora, urina com coloração escura e morte".

Ainda, para a pesquisadora,

A icterícia e anemia intensa geralmente estão associadas à anaplasmose e à hemoglobinúria com a babesiose. A Babesia bovis pode ocasionar sintomatologia nervosa e os bovinos afetados apresentam incoordenação dos membros posteriores e agressividade. Abortos podem ocorrer após a febre (Cassol, 2020). 
No que diz respeito às complicaç̃es advindas de infecção por babesia, Gonçalves (2020) destaca as seguintes:

- hipotensão;

- problemas hepáticos;

- colapso dos glóbulos vermelhos, conhecido como anemia hemolítica;

- falência renal;

- insuficiência cardíaca.

A TPB, por se tratar de um complexo envolvendo três agentes etiológicos, requer, segundo Quevedo e Quevedo (2020), o conhecimento do ciclo biológico desses agentes e suas condições epidemiológicas no sentido de relacioná-los à patogenia e aos sinais clínicos detectados, como forma de ser realizar o correto diagnóstico da TPB. Para isso, os pesquisadores apresentam, em seus estudos, uma tabela sobre as patogenias e sinais clínicos de cada agente etiológico da TPB.

Tabela 1. Agentes etiológicos da TPB com respectiva patogenia e sinais clínicos.

\begin{tabular}{|c|c|c|}
\hline Agente & Patogenia & Sinais clínicos \\
\hline Babesia bovis & $\begin{array}{l}\text { Mais patogênica, o grau de anemia é desproporcional a } \\
\text { parasitemia, é associada a deposição de hemácia a } \\
\text { pequenos capilares que no cérebro causa anoxia e lesão } \\
\text { tissular, pode ainda causar estase circulatória, choque e } \\
\text { coagulação intravascular. }\end{array}$ & $\begin{array}{l}\text { Hemoglobinúria, temperatura superior a } 41{ }^{\circ} \mathrm{C} \text {, } \\
\text { incordenação motora, andar cambaleante, } \\
\text { movimentos de pedalagem e agressividade. }\end{array}$ \\
\hline $\begin{array}{l}\text { Babesia } \\
\text { bigemina }\end{array}$ & $\begin{array}{l}\text { Rápida multiplicação do parasito e destruição de } \\
\text { eritrócitos. Menor virulência. }\end{array}$ & $\begin{array}{l}\text { Apatia, orelhas caídas, debilidade, febre, anorexia, } \\
\text { emagrecimento, pelos arrepiados, taquicardia, } \\
\text { taquipneia, redução dos movimentos de } \\
\text { ruminação, redução ou suspensão da lactação, } \\
\text { anemia e hemoglobinúria. }\end{array}$ \\
\hline $\begin{array}{l}\text { Anaplasma } \\
\text { marginale }\end{array}$ & $\begin{array}{l}\text { Período de incubação de } 4 \text { semanas, ocorre febre } \\
\text { parasitemia e com a evolução se torna mais grave, com até } \\
70 \% \text { dos eritrócitos destruídos. }\end{array}$ & $\begin{array}{l}\text { Apatia, orelhas caídas, debilidade, febre, anorexia, } \\
\text { emagrecimento, pelos arrepiados, taquicardia, } \\
\text { taquipneia, redução dos movimentos de } \\
\text { ruminação, redução ou suspensão da lactação e } \\
\text { icterícia }\end{array}$ \\
\hline
\end{tabular}

Fonte: Quevedo e Quevedo (2020).

Nesse sentido, o diagnóstico precoce desses agentes etiológicos é uma das formas de se evitar a contaminação de animais saudáveis, garantindo maior êxito no tratamento da parte do rebanho que não estiver contaminado.

Por ser facilmente confundidas com outras doenças, as patogenias e os sinais clínicos dos três agentes etiológicos que compõem o complexo TPB requerem diagnóstico cauteloso. Assim, embora possam ser realizados exames clínicos, faz-se necessária, para comprovar o diagnóstico clínico, a realização de exames laboratoriais, os quais irão detectar com precisão o tipo de agente e o melhor tratamento a ser aplicado à situação (Cassol, 2020).

O esfregaço sanguíneo, método mais prático e recorrente nesse tipo de diagnóstico, é o exame em que o sangue é colhido na orelha ou na extremidade da cauda do animal, para o qual se recomenda a realização de pelo menos três lâminas por animal. Já na sorologia, podem ser realizados testes de imunofluorescência direta (IFI), ou de conglutinação rápida (TCR), levando-se em consideração a análise geral de apresentação da enfermidade, a partir dos sinais clínicos e das patogenias observados (Martins, 2020).

De acordo com Quevedo e Quevedo (2020), alguns parâmetros podem ser definidos para auxiliar na análise da TPB:

[...] confirmação a partir de lesões macroscópicas juntamente com a realização da técnica denominada clapp (impressão do órgão na lâmina), do córtex encefálico seguido da coloração pela técnica de Giemsa [...]. Durante a avaliação em microscópio e auxílio de óleo de imersão é possível visualizar pequenas corpos arredondados ou corpos pareados em forma de pêra unidos em ângulo obtuso dentro de hemácias, estas estruturas possuem de $1-1,5 \mu \mathrm{m}$ 
(arredondados) e 1,5 - 2,4 $\mu \mathrm{m}$ (forma de pêra) [...]. Outra alternativa de diagnóstico definitivo possível utilizada é Método Panótico rápido. Com esta coloração é possível observar capilares do córtex encefálico repletos por hemácias contendo estruturas basofílicas solitárias ou pareadas de aproximadamente $2 \mu \mathrm{m}$ de diâmetro [...]. (Quevedo \& Quevedo, 2020)

O diagnóstico equivocado, ou impreciso, das doenças do complexo de TPB, além dos danos à saúde do rebanho bovino, impacta diretamente nos processos de melhoramento genético do rebanho nacional, em que o gado poderia ser colocado em áreas livres. Ademais, quando o diagnóstico não é feito a tempo, a morbidade e mortalidade nos animais, particularmente os da raça taurina (Bos taurus) ou seus cruzamentos, são significativas (Andreotti; Garcia; Koller, 2019).

A Tristeza Parasitária pode acometer qualquer categoria de bovino, entretanto, a categoria mais suscetível aos agentes etiológicos da TPB são os bezerros, os quais apresentam aguda sensibilidade imunológica, especialmente na fase de seus quatro meses de vida, contexto em que ocorre a transição da imunidade colostral para a imunidade adquirida. Os animais jovens são gravemente afetados, em razão à hematofagia, o estresse e a inflação ocorrida no local da picada, decorrentes da saliva tóxica (BRASIL, 2020). Além disso, a genética compreende outro fator importante nesse processo, uma vez “[...] bovinos de sangue europeu são mais susceptíveis aos carrapatos e aos agentes da TPB, enquanto animais zebuínos são naturalmente resistentes (Hellu \& Rezende, 2020).

Outro fator que contribui para as doenças da TPB deve-se ao fato de o carrapato-do-boi, principal vetor das doenças desse complexo, ter o crescimento de sua população diretamente relacionado às variações climáticas das diferentes regiões do país. Assim, estados da Região Centro-Oeste, por exemplo, apresentam clima favorável para a proliferação desse vetor, além de possuírem forte presença de raça bovina holandesa, proveniente da Europa, e de gado girolando, cruzamento entre o holandês e a raça Gir.

A dinâmica populacional do carrapato, a depender do clima de uma região, pode chegar até a $4^{\mathrm{a}}$ geração, particularmente tropicais, subtropicais e de clima temperado. Na figura 1, verifica-se a dinâmica da população do carrapato-doboi no Brasil, conforme o clima de cada mês.

Figura 1. Modelo da dinâmica da população do carrapato-do-boi no Brasil.

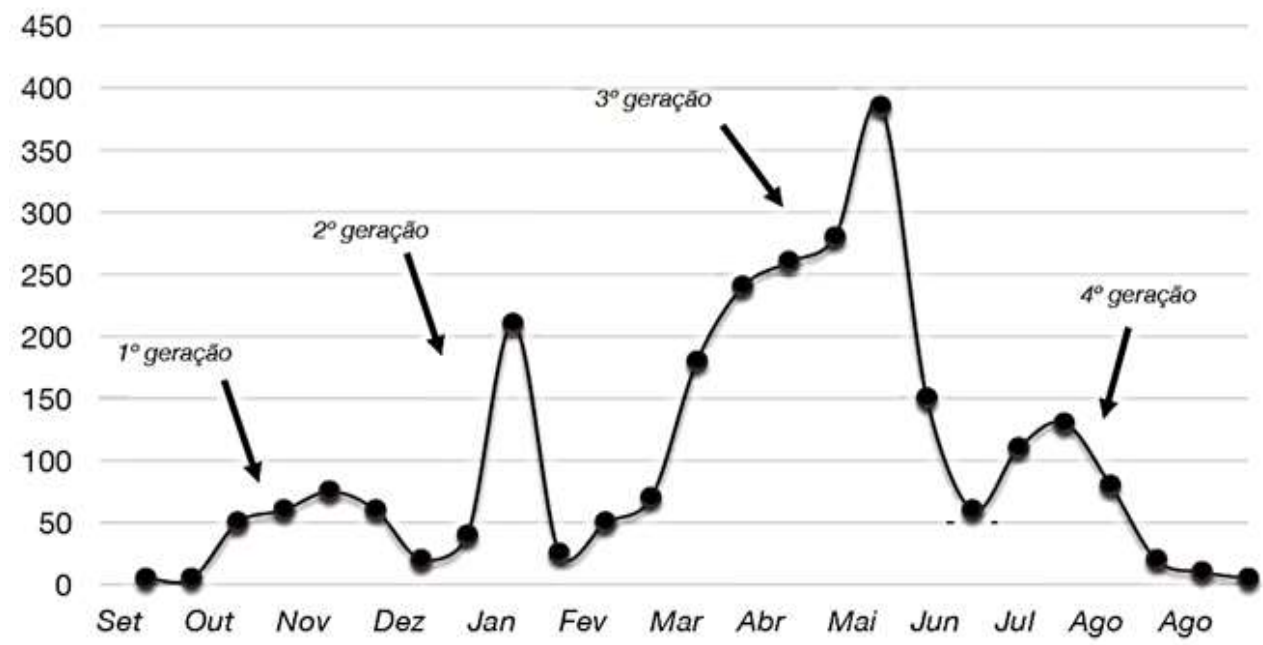

Fonte: Brasil (2020). 
Como se pode observar, a frequência de carrapatos é variável ao longo do ano, de modo que, as formas jovens podem se fazer presentes no mês de setembro, em regiões com clima mais quente, enquanto o mesmo fenômeno pode acontecer apenas no mês de outubro nas regiões de clima mais frio (Brasil, 2020).

Sob condições de manejo inadequadas, a TPB encontra requisitos favoráveis para seu desenvolvimento. Por exemplo, num processo de vacinação, em que uma mesma seringa é utilizada para vacinar um rebanho inteiro, corre-se alto risco de contaminação, assim como no manejo de instrumentos cirúrgicos contaminados.

Para Andrade e Simplício (2019), a adoção imediata de plano terapêutico baseado apenas na suspeita de diagnóstico, representa um entrave para uma anamnese bem elaborada, já que, geralmente, o processo deve estar atrelado à realização do exame clínico em conjunto com exames laboratoriais, bem como deve contar com a presença profissional de um clínico que possa identificar e notificar corretamente casos de TPB.

Embora não haja, no Brasil, estudos que comprovem a transmissão transplacentária de A. marginale, pesquisam no mundo todo tem apontado para essa frequente situação (Brito et al., 2019). Ademais, há que se considerar a resistência do carrapato aos diversos produtos aos quais ele é exposto durante os processos de controle e tratamento da TPB, contexto em que esse vetor desenvolve capacidade fenotípica e/ou genotípica à toxidade dos produtos, tonando-se multirresistente (Brasil, 2020).

Dada a alta capacidade fenotípica e/ou genotípica desenvolvida pelo principal vetor de transmissão da babesia e da anaplasmose (o carrapato Rhipicephalus microplus), diversos processos de controle e tratamento foram implementados ao longo dos anos no país, desde banhos de querosene e óleo de algodão, inseticidas sintéticos, e controle preventivo com o uso de diferentes drogas (BrasiL, 2020).

De acordo com Molento (2020), embora o número de medicamentos tenha crescido nos últimos anos, não houve diminuição significativa nem do carrapato nem das doenças transmitidas por ele, já que o número de mortes e contaminação apresenta altas taxas anuais. O pesquisador destaca o fato de que o controle do carrapato é feito de forma preventiva, e não há processos de seleção entre animais contaminados e animais saudáveis, ou mesmo daqueles que adquirem resistência ao carrapato, além do fato de se fazer uso de medicamentos em sequência e com grande frequência, o que contribui para a existência de carrapatos multirresistentes aos produtos aplicados.

Para o estudioso, é preciso implementar protocolos específicos, que levem em consideração caso por caso, adotandose medidas mais seguras e de longo prazo para que se observe adequadamente o nível de tolerância tanto do parasito quanto do hospedeiro, mas que também se observem os possíveis desequilíbrios na relação parasito-hospedeiro.

Os principais tratamentos no combate ao carrapato Rhipicephalus microplus no Brasil compreendem o uso de alopáticos (acaricidas químicos), de homeopáticos, e o controle dos vetores (carrapatos e moscas).

No caso da babesiose, Quevedo e Quevedo (2020) destacam os principais fármacos para esse tipo de situação (Tabela 2.):

Tabela 2. Tratamento da babesiose. Princípio ativo, dose e frequência de administração.

\begin{tabular}{l|l|l} 
Princípio ativo & Dose & Frequência \\
\hline Diace/turato de diminazina & 3 a $5 \mathrm{mg} / \mathrm{kg}$ & $2-3$ aplicações a cada $24 \mathrm{~h}$ \\
Dipropionato de imidocarb & 1 a $3 \mathrm{mg} / \mathrm{kg}$ & $2-3$ aplicações a cada $24 \mathrm{~h}$
\end{tabular}

Fonte: Quevedo e Quevedo (2020).

Estudos desenvolvidos por Ulsenheimer et al. (2020) em bovinos leiteiros em Ijuí-SC, refratários à utilização de oxitetraciclina, têm demonstrado a eficiência da enrofloxacina no tratamento de surto de anaplasmose na área estudada. Os pesquisadores detectaram, após a verificação de achados de necropsia e da realização de esfregaço sanguíneo, não só a 
existência de surto de anaplasmose na região, mas também a existência de cepas da A. marginale resistentes ao tratamento com oxitetraciclina, o que os levaram ao uso da enrofloxacina como forma alternativa para lidar com a situação, de modo que os resultados apontam para dados satisfatórios, embora seja necessário pesquisa mais ampla sobre o tratamento e controle das variáveis envolvidas num estudo como esse.

De acordo com Brito et al. (2015), o controle parasitário feito unicamente pela aplicação de diversificados produtos químicos de fácil acesso e manuseio criados pela indústria farmacêutica veterinária se mostrou uma falsa ilusão ao longo dos anos, visto que logo se constatou, no estudo epidemiológico de parasitas ruminantes, o aparecimento de resistência às bases químicas parasiticidas mais aplicadas.

No Brasil, o controle das populações de carrapatos que infestam os rebanhos bovinos se dá pela utilização de uma ampla gama de pesticidas, porém, devido ao baixo custo relativo, os grupos químicos piretróide, organofosforado e amidina são os de uso mais comum, lembrando que, a amidina não possuí indicação de uso para o controle das infestações causadas pela mosca-dos-chifres. A disseminação da resistência às diferentes bases pesticidas demonstra as limitações existentes no controle químico parasitário, sendo essencial que as bases parasiticidas sejam administradas como preciosos recursos no âmbito do manejo sanitário dos rebanhos (Brito et al., 2015).

Diante desse quadro, observou-se que, além do tratamento tradicional com alopáticos, o uso de homeopáticos e de rotação de pastagens tem se mostrado como alternativa para o tratamento de infecções por babesia e por anaplasma, embora os resultados ainda sejam pequenos quando comparados aos métodos tradicionais, é o que relata o estudo desenvolvido por Kemer et al. (2020), no qual os pesquisadores investigaram o uso de métodos convencionais e alternativos para o controle do carrapato em 18 propriedades rurais na região do planalto serrano catarinense. Os dados apontaram que, das 18 propriedades, 6 utilizam práticas homeopáticas e rotação de pastagem como método de controle e tratamento de TPB, sinalizando baixa infestação nos rebanhos em relação aos métodos tradicionais das demais propriedades.

Buscando alternativas mais eficazes e seguras para combater e/ou controlar a proliferação das populações de carrapatos no rebanho bovino brasileiro, o Ministério da Agricultura, Pecuária e Abastecimento lançou em 2020 o livro "Avaliação Seletiva de Bovinos para o Controle do Carrapato Rhipicephalus microplus", em que é apresentado um extenso estudo epidemiológico sobre o carrapato-do-boi, e a interação parasito-hospedeiro, observando-se as variáveis comportamentais desse parasito em diversos contextos, para apresentar possíveis estratégias para combatê-lo (Brasil, 2020).

Entre as soluções propostas pelo órgão está o "Tratamento Seletivo dos Bovinos" (TSB), "uma técnica auxiliar no controle do carrapato, visando mitigar o aparecimento de resistência aos acaricidas" (Brasil, 2020).

O TSB faz parte do SICOPA - Sistema Integrado de Controle Parasitário e visa assegurar o controle efetivo de parasitos, com a individualização do tratamento, conhecendo melhor a resposta dos animais. O TSB propõe um novo formato na relação com os bovinos e o uso adequado dos medicamentos, viabilizando também que novas recomendações possam ser implementadas nas propriedades. O método seletivo, permite ainda, identificar animais mais tolerantes aos carrapatos (seleção fenotípica), implementando uma rotina de observação criteriosa, além de promover uma abordagem alternativa e de transição para criadores em sistemas agroecológicos (Brasil, 2020).

O propósito do material é orientar acadêmicos, pesquisadores e profissionais sobre práticas sanitárias que levem à longevidade da vida bovina, a partir de medidas de mitigação da resistência parasitária. Entre os objetivos do TSB, verifica-se:

1. otimizar o uso de produtos químicos, 2. reduzir a pressão de seleção, por tratar somente os animais com maior contagem de carrapatos (os mais infestados), 3. reduzir a contaminação ambiental, 4. melhorar os índices clínicos e zootécnicos dos animais, 5. facilitar o manejo e reduzir o estresse causado aos animais durante a aplicação de produtos, 6. reduzir os custos da propriedade, e 7. possibilitar a seleção de animais mais tolerantes, após a observação continuada dos animais (Brasil, 2020). 
Nesse sentido, a metodologia do TSB envolve a contagem de carrapatos em apenas um lado do animal, contexto em que são tratados apenas os animais que apresentem mais de 20 carrapatos, acima de 4,0 $\mathrm{mm}$, processo que deve ser realizado por técnico qualificado e treinado cujo objetivo é "[...] manter carrapatos que possam diluir o efeito da seleção de populações resistentes (Brasil, 2020).

Localizados os grupos de animais com mais infestação, aplicam-se níveis de controle, levando-se sempre em consideração a quantidade de carrapatos em cada animal, além de se observar os sinais clínicos e o grau de desconforto apresentado pelo animal.

As vantagens dessa metodologia visam:

1. Melhorar o manejo dos animais, com menos estresse de manipulação.

2. Reduzir o uso de medicamentos, com a avaliação individual.

3. Reduzir o risco de intoxicação medicamentosa.

4. Reduzir o volume de químicos com menor contaminação ambiental.

5. Reduzir a pressão de seleção para a resistência do carrapato.

6. Diluir populações de carrapatos resistentes com a refugia local.

7. Treinar mão-de-obra especializada.

8. Melhorar a relação custo-benefício com tratamentos pontuais.

9. Identificar animais resilientes e tolerantes ao carrapato.

10. Permitir a seleção intra-rebanho de animais muito tolerantes (BrasiL, 2020, grifos do autor).

No que diz respeito às particularidades da TPB, a metodologia supracitada tem como foco o controle mínimo do carrapato para equilibrar a relação vetor-doença, porém, garantindo a estabilidade ezoótica das doenças do complexo. Ademais, permite a redução de custos com medicamentos, já que a frequência de aplicação de acaricidas é controlada de forma segura por especialistas da área, o que representa, embora não totalmente avaliado no estudo, a redução de impactos ambientais, ou seja, o número de doses é reduzido, consequentemente o descarte de material prejudicial em leitos de rios e bacias hidrográficas reduz significativamente.

Embora estudos tenham comprovado a eficácia do TSB no controle do carrapato e sua ampla vantagem econômica, sua implementação esbarra no investimento de mão de obra, uma vez que é preciso realizar treinamento de pessoal, bem como fazer avaliações periódicas. Nesse sentido, criou-se o "Programa de Controle Seletivo do Carrapato Bovino" (PCSCB) para auxiliar no controle do carrapato a partir da realidade de cada local (Brasil, 2020). O programa é voltado para o auxílio de técnicos, veterinários e pesquisadores para que eles tenham condições de dar repassar técnicas diferenciadas de controle do parasito e possam contribuir na melhoria da saúde bovina do país.

O PCSCB foi desenvolvido pela Universidade Federal do Paraná (UFPR) e tem como foco o desenvolvimento de metodologias diferentes e sustentáveis que visem a diminuição do uso de produtos químicos no controle dos carrapatos e evitese a manipulação sem necessidade dos animais saudáveis. Assim, o programa requer a conscientização de técnicos e agentes do campo, para que se implementem estratégias inovadoras cuja finalidade é o desenvolvimento de um mundo mais crítico, complexo e sustentável, segundo o pesquisador Molento da UFPR, em entrevista para a "Rádio Cidade 670" (2019).

\section{Conclusão}

A Tristeza Parasitária Bovina é um desafio para o desenvolvimento econômico e para a saúde do rebanho brasileiro. Diversas metodologias com técnicas diferenciadas foram desenvolvidas ao longo dos anos para controlar, ou mesmo eliminar a propagação do principal vetor responsável pelas doenças infecciosas do complexo TPB, a Babesia e a Anaplasmose.

Muitas são as variáveis que contribuem para o insucesso na erradicação do parasito Rhipicephalus microplus, especialmente as condições climáticas da maior parte das regiões brasileiras, em que o clima tropical, subtropical ou quente contribui para a persistência dessa população durante todo o ano. 
O manejo sanitário inadequado é outro problema enfrentado nesse contexto, visto que muitas pesquisas atentam para essa questão. Ademais, o uso indiscriminado de produtos químicos sem a devida orientação técnica e profissional também acirra a difícil realidade enfrentada na criação de bovinos leiteiros ou gado de corte, já que se viu que o carrapato pode criar resistência a diversos produtos e/ou famílias de agentes químicos.

Embora a aplicação de produtos químicos ainda seja a prática mais recorrente para o tratamento do parasito Rhipicephalus microplus, é importante que se considere que a erradicação ou o controle desse parasito só tem êxito quando se leva em conta as particularidades de cada contexto, ou seja, de cada rebanho estudado e tratado, conforme destaca o Programa de Controle Seletivo do Carrapato Bovino, da Universidade Federal do Paraná.

Uma vez que a TPB é tão impactante para o desenvolvimento econômico das propriedades e bem estar animal, estudos com novas tecnologias devem ser estimulados, a fim de reduzir a ocorrência dessa enfermidade.

\section{Referências}

Andrade, C. T., \& Simplício, K. M. M. G. (2019). A importância do diagnóstico terapêutico a campo: relato de caso. Anais da VI Semana de Medicina Veterinária, UFAL.

Andreotti, R., Garcia, M. V., \& Koller, W. W. Controle estratégico dos carrapatos nos bovinos. (2019). Recuperado de https://www.embrapa.br/busca-depublicacoes/-/publicacao/1107102/controle-estrategico-dos-carrapatos-nos-bovinos.

Brasil. Ministério da Agricultura, Pecuária e Abastecimento. (2020). Avaliação seletiva de bovinos para o controle do carrapato Rhipicephalus microplus. Secretaria de Inovação, Desenvolvimento Rural e Irrigação. Brasília: MAPA.

Brito L. G. (2015). Diagnóstico de resistência às bases carrapaticidas em populações do carrapato dos bovinos. In: Veríssimo, C. J. (org.). Resistência e controle do carrapato-do-boi. Nova Odessa: Instituto de Zootecnia.

Brito, L. G., Barbieri, F. S., Ferreira, T. A. A., Carneiro, D. S., Amaral, T. M., Figueiró, M. R., \& Oliveira, M. C. S. (2019) Transmissão congênita de Babesiabovis e Anaplasma marginale na epidemiologia da tristeza parasitária bovina. In: Circular técnica 48. Belém-PA: Embrapa, 2019.

Camargo, S. A. B., Severo, T. H., \& Vidal, M. B. (2017). Controle biológico do carrapato bovino Rhipicephalus (boophilus) microplus por aves encontradas no bioma Pampa. Anais da $14^{a}$ Mostra de Iniciação Científica. Bagé: URCAMP, 53.

Cassol, D. M. S. (2020). Tristeza Parasitária Bovina (TPB) “Tristezinha”, "Pindura”, "Piroplasmose” ou "Mal da ponta”.

Gonçalves, F. (2000). Epidemiologia e controle da tristeza parasitária. Ciência Rural, 30(1), 187-194, 2.

Hellu, J. A. A., \& Rezende, E. H. C. (2020). Tristeza parasitária bovina, como prevenir e tratar essa doença? Recuperado de: www.jasaudeanimal.com.br IBGE. Instituto Brasileiro de Geografia e Estatística. (2020). Rebanho bovino reduz em 2018, em ano de crescimento do abate e exportação.

Kemer, A., Machado, B. J. A., Comelli, D., Glienke, C. L., \& Tavela, A. O. (2020). Manejo sanitário e a ocorrência de carrapatos em propriedades na região do planalto serrano Catarinense, Sul do Brasil. Braz. J. Anim. Environ. Res., 3(2), 602-615.

Martins, G. M. Tristeza parasitária bovina: à espreita do hospedeiro. 2020. Recuperado de: https://www.comprerural.com/tristeza-parasitaria-bovina-aespreita-do-hospedeiro/

Milkpoint. (2020). Como diferenciar a tristeza parasitária da tripanosomose bovina? https://www.milkpoint.com.br/canais-empresariais/ceva/comodiferenciar-a-tristeza-parasitaria-da-tripanosomose-bovina-208694/

Molento, M. B. (2020). Avaliação seletiva de bovinos para controle do Rhipicephalus microplus. Ars Veterinária, , $36(1), 1-2$.

Pasquali, A. K. S., Carmo, P. G., Sanguanini, G., Costa, J. D., Luiz, R. R., \& Griebler, T. S. (2019). Presença do carrapato Rhipicephalus (Boophilus) microplus em bovino da raça mestiça. Seminário de Iniciação Científica e Seminário Integrado de Ensino, Pesquisa e Extensão.

Quevedo, L. S., Quevedo, P. S. (2020). Aspectos epidemiológicos, clínicos e patológicos da babesiose bovina. Pubvet, 14(9), a650, 1-7.

RADIO CIDADE 670. (2019). UFPR cria programa sustentável para o controle de carrapato em bois.

Silva, T. F., Alves-sobrinho, A. V., Lima, L. F. S. de, Ziemniczak, H. M., Ferraz, H. T., Lopes, D. T., Silva, V. L. D. da, Braga, Ísis A., Saturnino, K. C., \& Ramos, D. G. de S. (2021). Bovine parasite sadness: Review. Research, Society and Development, 10(1), e15410111631.

Ulsenheimer, B. C., Schvan, D. E., Shifer, J. L. L., Fontoura, R. P., \& Teichmann, C. E. (2020). Uso da Enrofloxacina em surto de anaplasmose em bovinos leiteiros em Ijuí- RS: relato de caso. Pubvet, 14(3), a650, 1-7. 